\title{
Emotional Suppression and its Relationship to Persecutory Thinking
}

\author{
Dr. Ammar Abd Ali Hassan \\ Faculty of Education- Ibn Al Haitham for Pure Science/ Department of Educational and Psychological Science
}

\begin{abstract}
The aim of the study was to find the correlation between emotional repression and oppressive thinking and to identify the level of emotional repression and the oppressive thinking of the sample members and to identify differences according to the two sex variables. The study sample consisted of 400 students (male and female), They were selected from four faculties of the University of Baghdad, two faculties of scientific specialization and two colleges of human specialization with 200 male students and 200 female students.In order to achieve the research objectives, two measures were adopted (for emotional suppression and another for oppressive thinking). In the current research, the cykometric properties of the validity, consistency and discrimination of vertebrates were extracted. The results showed that the research sample had an emotional suppression and that there were differences between males and females in favor of females. The results of the study showed that the research sample has a compulsive thinking. There are no differences between males and females. There is a positive correlation between emotional suppression and oppressive thinking (0.73). The research ended with a number of recommendations and suggestions.
\end{abstract}

\section{Research Problem}

The problem of research is that emotional repression is a summary of the efforts and attempts of the individual to control the expressions of emotional experience, a strategy aimed at reducing or effectively removing the behavior of emotional expression and includes negative expressions andpositive emotional as well., And some experimental studies indicate that attempts to suppress positive emotions have an impact on the facial expressions, while does not affect the suppression of negative emotions in those terms, The effects of repression on both types of emotions are still uncertain (Nezlek * Kuppens, 2008, p.4). Many previous studies have examined and followed the links of emotional repression and its negative psychological and mental effectsindirectly and in the long term.

The results of the previous studies showed the presence of long and short-term negative effects with both external and internal effects. The external effect of the suppression is directed towards the interactive function of the suppressed individuals. The Butler et al. 2003 study indicates an increase in physical response in individuals who interact socially with individuals who are emotionally receptive to dealing with them. As opposed to a decrease in the tendency to establish harmony and intimacy towards them, as well as a decrease in the tendency to establish social connections such as friendship and others, as demonstrated by the results of the Reis * Shaver study in 1986Individuals who follow the repression strategy to control their emotions are unable to establish intimate relationships with others or even to close existing relationships. This is attributed to the weakness of the individual's perception of the emotions of the other, which is the most important ability for the success of the interactive side of the individual with whom around him ((Schneider, 2008, pp.23-25).

The psychological consequences of emotional repression in many aspects include the mental and social aspects of the individual. Persistent and often effective attempts to conceal or reduce the manifestation of emotional expression behaviors when emotional excitation actually takes effect $j$ In the event of an emotional arousal, the effect of these attempts in the lives of productive individuals is the line of repression, which often end up with other social problems such as avoiding communication, poor social participation, low social support,and the use of inappropriate attachments in many lives, as well as attempts to destroy the strong relationships in their lives (Butler et.al.2007, p.31).

Several previous studies have pointed to differences in the results of negative emotions inhibition of negativity. The Nezlek and Kuppens study indicated that the suppression of positive emotion is associated with a lower level of selfesteem, decreased psychological compatibility,, And increased frequency of negative emotions such as grief and anxiety in the future, while the restraining of negative emotion was associated with a high level of self-esteem and high anxiety, (Nezlek * Kuppens, 2007, p10).

Repression, moreover, is under the list of factors involved in the formation of the case of experiential avoidance, which is characterized by the behavior of avoiding or escaping unpleasant personal experiences. Nevertheless, the consequences of complying with repression are much worse than other forms of the state of avoidance, as the repression works to curb the emergence of the response after its development.

Other forms of avoidance may evade situations that originally predict the evolution of the emotional response. Campbell-Sills * Barlow noted in 2007 that emotional regulation by means of his means is usually associated with the development of a number of psychological crises that later develop into disorders.

This results in an overstatement of the technique of chronic suppression, which is associated with post-traumatic stress disorder, obsessive-compulsive disorder, depression, general anxiety disorder, and phobias (Pedneault et al., 2010, p.141).

We live in a time where the vocabulary of life has become more complex and demanding, and the pressures of all kinds have increased and intensified. And the multiplicity of 


\section{International Journal of Science and Research (IJSR) \\ ISSN (Online): 2319-7064}

Index Copernicus Value (2016): 79.57 | Impact Factor (2015): 6.391

ambitious goals and multiple types of obstacles with them, and these and other things put the human in front of various problems require appropriate solutions, Since the solution of problems, according to Mayer, represents the thinking (Mayer, 1977, p.6), but represents the top of thinking, logic leads us to conclude that it is difficult for a man of thinking of the type of oppression to reach solutions to his problems with the same ability and success compared to another, his thinking is rational of the feelings of oppression, and not at the same level of the state of psychological, social and professional compatibility of another individual who does not think of the type of oppression (Saleh, 2000 p. 3).

Deprivation means that a person feels oppressed, oppressed, oppressed, unjust, unfair, or deprived of a right to life, and other beliefs that may be false, but it may provoke within it aggression that may be expressed in a conflict, and may keep it suppressed, and may remain this level of acceptable, and may turn into illusions and then may be described as infected (paranoia) (Saleh, 2000 p.1).

Exposure to disorders such as anxiety disorder, which leads a university student to be isolationist and behavior involves suspicion of others and expect others to exploitation, harm and deception and cannot establish an intimate relationship with others and often feel that his personality(Exposure to disorders such as anxiety disorder, which leads a university student to be isolationist and behavior involves suspicion of others and expect others to exploitation, harm and deception and cannot establish an intimate relationship with others and often feel that his personality.

Does the research sample have an oppressive and oppressive thinking and is there a relationship between them?

\section{Importance of research}

The importance of research The importance of emotional repression - one of the strategies of organization - appear in situations where the individual starting to express his negative emotions strongly - such as anger - which affects the threat to the life of the individual through the injury of heart attacks, and here it requires to curb the severity of the importance of research The importance of emotional repression - one of the strategies of organization - appear in situations where the individual starting to express his negative emotions strongly - such as anger - which affects the threat to the life of the individual through the injury of heart attacks, and here it requires to curb the severity ofMay make it easier for the individual to strengthen ties and maintain a network of social relations (Bonanno et al., 2003, p. 2).

The feeling of stress as a result of the method of repression indicates a dangerous beginning in terms of physical and psychological health of the individual, which is the beginning of the logic of depression and anxiety, and the high incidence of cancerous tumor, as this increased tension and accumulated in the inside to weaken the ability of The immune system of the body in the face of disease, usually associated with the incidence of fatal diseases nature of the emotional state of the individual, emotions as an important psychological energy affect the weakening of body resistance and defenses, (Issawi, 2008, pp. 80-82).

The psychological and psychological aspects of the individual are always changed. Emotional expression or feeling is healthy. Repression is necessary in situations where restraint is required. Emotions are messages that come from the inner desires and the inner voice of each of us.This hidden energy will turn inside, interfering with vital and important processes. McLaren recalls in 2010 in her book 'languages of emotions'.

That the unconscious option will either increase the intensity of the emotion and submit it later in more than a time (this shows how the suffering of emotions and tensions tense and untreated show its effect), or may take the mind the second option is to abandon them and hide this energy is congested in depth, at this point, expressive desire will not translate and understand as it is in its initial form (in anger or fear or both), but retain its original intensity and all associated information, and this intensity will often change later to include other symptoms such as : Tics, Compulsion, Cycosomatic Diseases, Addiction, or Neurological Tensions. Thus, continuous and continuous repression will not be a path but a loss for individual therapy (Mc Laren, 2010, p.31).

The oppressive thinking is one of the most serious disorders because its characteristics are available in varying degrees of intensity in all people, regardless of their race, race, culture, cultural and social environment, and if it increases its severity from the natural borders becomes a satisfactory condition requires dealing with the its owner on this basis (Kamal, 1987 223).

Because of the sensitivity of the owner of the zodiacal personality, the information processes become highly selective. Any evidence, however trivial, seems to agree or support an idea in his head, amplifying it as a comprehensive and categorical guide, ignoring all the data Which contradict or misinterpret it (DSM IV; APA, 1994).

In light of this, the standards of good behavior, influenced by the quality of the content of the thought carried by one and the manner of implementation of his ideas in the acts and behavior, and thinking the challenges components identified in this research, the bias of self-service, suspicion and mistrust,Infidelity, injustice (or injustice) and restricted effectiveness are one of the main factors in abnormal behavior, inadequate behavior, and uncomfortable behavior of the partner, and it negatively affects the good perception of reality, self-knowledge, the exercise of voluntary control of the ego, (PPD) has multiple negative effects at the individual, family and community levels, some of which are dangerous, sometimes amounting to the commission of a crime (Saleh, 2000, p. 13).

\section{Research Objectives}

The present research aims to measure:

1) The emotional repression of university students.

2) Measuring the differences in the level of emotional repression according to the gender variable (male female). 


\section{International Journal of Science and Research (IJSR) \\ ISSN (Online): 2319-7064}

Index Copernicus Value (2016): 79.57 | Impact Factor (2015): 6.391

3) Measurement of oppressive thinking among university students.

4) Measuring differences in the level of oppressive thinking according to the gender .variable(male and female)

5) Measuring the correlation between emotional repression and oppressive thinking

\section{Limits of research}

1) The current research is determined by the students of Baghdad University for both sexes for the academic year (2016-2017) of the variables (emotional repression, oppressive thinking). Definition of Terms Emotional Suppression was defined by Richard and Gross"((Curbing the issuance of expressive signs of internal emotional situations.

2) The researcher adopted the definition of Richard and Kruz theoretical definition of the variable of emotional repression either the procedural definition that the degree of the total obtained by the respondent on the paragraphs of the measure of emotional repression.

3) Perspective Thinking The American Psychiatric Association (APA) is a comprehensive pattern of mistrust and suspicion of others to explain their motivations as being hateful and starting in early adulthood and appearing in diverse contexts (APA, 1994, p.634).
The researcher adopted this definition, either the procedural definition as the total degree obtained by the examinee on the paragraphs of the scale of oppressive thinking.

\section{Theoretical Framework}

The Theory of James Cross Gross Theory 1998-2001 Cognitive Theory The theory of James Cross is one of the most important theories currently practiced on the subject of the interpretation of emotional regulation in general and emotional repression in particular. The theory in its articles refers to the nature of persons In order to understand these strategies clearly, it is necessary to return to the subject of emotion, and to that model called (Modal Model of Emotion). Which gives the emotion three real features, namely the interaction between the individual and the man, which requires attention, and in Figure (1), the reference to a simplified explanation of the concept of this formality model, which is the interaction between the stimulant and the response and average processes of attention and evaluation of the an assessment of the stimulus and how to respond to it coupled with the occurrence of neurological and behavioral changes depending on the type of response

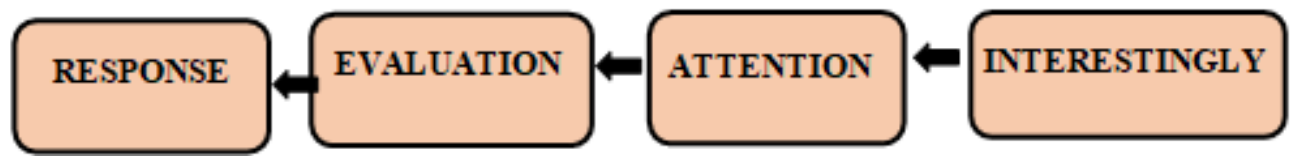

Thus, the five organizational strategies can be referred to based on the previous form. The emotional regulation includes the following strategies: (a) The selection of the situation

B. Modulation Modification c. Attention Attentional Deployment d. Cognitive Change. e. Response Modulation. In his theory, Crosse emphasized the nature of individuals in trying to regulate their emotions by various means. His explanation of regulation stems from the process of generating emotion, which indicates that the emotion arises from the individual's assessment of signs and emoticons in the environment.After the necessary assessment, the physiological, neurological and behavioral changes are resolved to achieve the desired goal, the response is formed in various ways, and because the emotional nature is evident, the best way to distinguish the processes of emotional regulation is to determine the time of intervention during the course of generating emotion must be distinguished. These strategies need to be distinguished. There are previous concentration strategies and subsequent concentration strategies. The first includes all the abovementioned processes that take place before an assessment of the appropriate stimulus and response, While the second refers to all processes that occur during the evaluation of the conscience and the consequent response to the stimulus (Gross * John, 2003 p.348).

The four strategies (selection of stimuli, modulation of stimuli, diffuse attention and cognitive change) are from previous processes, and the strategy of response formation is one of subsequent processes, namely, the selection of the stimulus (the search process or the avoidance of a situation or someone in the environment to achieve the control of the emotions), while the transformation of the stimulant to (the process of adaptation in the stimuli and adapted to affect the effects of emotions, which makes it in the end exciting different from the previous, and the process of attention is spread to the intended (the distribution of attention to capture aspects of the environment and focus on it, The process of shaping the response, which means 'multiple and multiple attempts to influence the nature of the emotional response as soon as they arise and form', John * Gross, 2004, p.1304). Figure 2 explains this strategy.

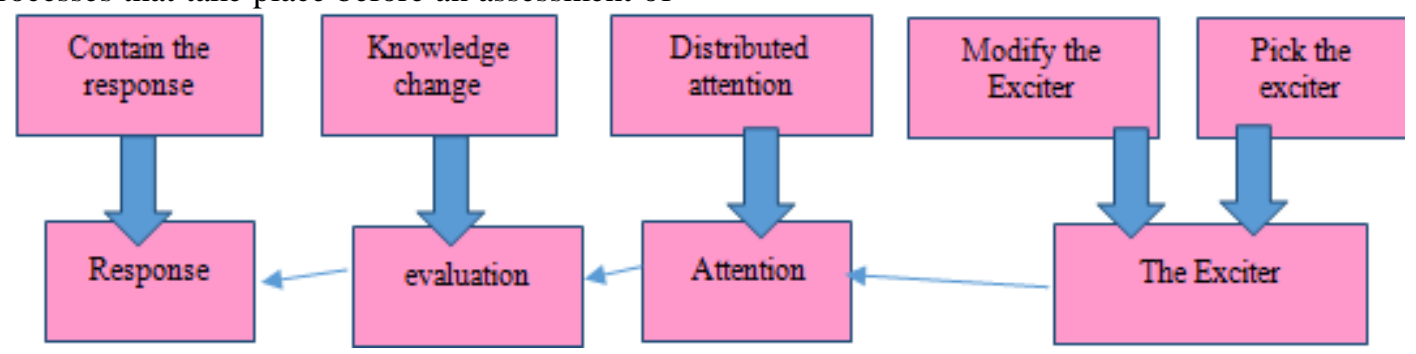

Volume 6 Issue 12, December 2017 www.ijsr.net 


\section{International Journal of Science and Research (IJSR) \\ ISSN (Online): 2319-7064}

Index Copernicus Value (2016): 79.57 | Impact Factor (2015): 6.391

Each (2) is a practical model of emotional regulation that highlights the five categories of emotional organization strategies (Gross, 2007, p.10).

The organizational strategies take several forms to show their effectiveness with emotional force, depending on the individual's cultural and intellectual background, the nature of the situation and the required control and control. $\mathrm{He}$ often follows the design of the strategies of the organization created by Crosse in 1998,, Which distinguishes between two types of strategies followed, the first and called the term (Reapraisal), and the second term (Suppression) (Suppression), and includes the first term (a change in the way the individual interprets the situation and thus reduce the emotional impact is a formula of strategic formulas.Cognitive change), while the second term (suppression of signals from internal feelings, a form of response formation), and previous studies indicate that both methods are different in their consequences, that the strategy of re-evaluation associated with the lack of the emotional experiments, , (Nezlek* Kuppens, 2008, pp. 562-563).

The reasons for distinguishing these 5 strategies from others strategies.The first is the importance of the chosen strategy to be common in everyday life, and the second is that the chosen strategy should allow the use of experimental treatments and analysis of individual and third differences.is that the difference between past and subsequent operations, as Crosse in his classification selects the center-centered process of cognitive change as the representative of the previous processes, and chooses the process of response formation as a later process (John * Gross, 2004, p1304).

In a study by Lisa Fusto and her colleagues in 2010 to study the effect of emotional repression on self-abuse, such as persistent smoking, for example, , Pointed out that continuous and long-term smoking was associated with individuals who expressed expressions of sadness or anger when they saw a video tape of an influential nature, while such behavior was reduced by those who follow other organizational means, and indicates the association of emotional repression in particular to parents (Fucito et.al ., 2010 , p.1156).

In reference to depression and anxiety, the study of Spokas and his colleagues Spokas et.al. In 2009, there was a strong correlation between the high level of anxiety among individuals and the suppression of their emotions and ideas. He conducted a study to measure the level of anxiety among 95 university students and the extent to which they followed the method of oppression by followers the measurement, the sample was divided into three sections of high anxiety, moderate anxiety, and low anxiety. The first group was the most repressive of feelings and the least ability to express and describe their emotions from the other two groups, The study attributed the reason that the oppressive individual feels his social incapacity and his inability to mix and harmonize with his surroundings as a result of the continuous repression, which weakens the social bonds around him and thus leaves him a victim of concern, especially social ones (Spokas et.al., 2009, pp.285-289).

In his study of repression, Cros said that prolonged and prolonged repression would lead to the loss of originality and substance, which aims to discriminate against the individual and thus cause loss to the individual's attempts at social integration and loss of self to achieve social acceptance and non-exposure toTo any rejection of society, and these individuals recognize their followers in ways and methods to make the other fantasize about the reality of their intents and feelings, and thus conclude that their oppressive attempts increase whenever the link is important or useful to the individual and is afraid of losing the recognition of the fact of what he thinks or feels(John * Gross , 2004, p.1313).

\section{The Oppressive Thinking}

The control of the method of emotional repression extends to the behavior of the individual and not only to control emotions and thinking, In a study conducted by Lisa Fusto and her colleagues in 2010 to study the effect of emotional repression on the continuation of self-harming methods such asconstant smoking, pointed out that continuous and longterm smoking was associated with individuals who expressed expressions of grief or anger when they saw a video tape of an influential nature. Such behaviors were reduced by those who follow other organizational means, And the association of emotional repression in particular with the motivation for smoking, especially when depressed and distressed, (Fucito et al., 2010, p.1156).

In reference to depression and anxiety, the study of Spokas and his colleagues Spokas et.al. In 2009, there was a strong correlation between the high level of anxiety among individuals and the suppression of their emotions and ideas. He conducted a study to measure the level of anxiety among 95 university students and the extent to which they followed the method of oppression by followers andAfter the measurement, the sample was divided into three sections of high anxiety, moderate anxiety, and low anxiety. The first group was the most repressive and least able to express and describe their emotions from the other two groups. The study attributed the reason that the oppressive individual feels his social incapacity and his inability to mix and harmonize with his surroundings as a result of the continuous repression, which weakens the social bonds around him and thus leaves him a victim of concern, especially social ones (Spokas et.al., 2009, pp.285-289).

Despotional thinking refers to a severe, irrational (and irrational) type of permanent mistrust and mistrust of people, and a constant tendency to interpret the actions of others as an intentional or insulting threat (Costello, 1996, p.242). And because there is a general expectation that others are against them or are trying to be cautious, cautious and cautious, and are constantly looking for evidence or information indicating that there are bad intentions against them, those close to them, and their disloyalty to them.They tend to emphasize these expectations with ease, because their excessive sensitivity makes them interpret or turn the simple contempt into a big insult, and the frivolous acts into large harmless and deliberate events, and will result, in turn, in painful events, accompanied by the expectations of others To painful events, accompanied by expectations of treachery, treachery or hostility, often provoke reactions that confirm their expectations and justify their doubts and hostility toward others (Fenigstein, 1995a, p.230). What

\section{Volume 6 Issue 12, December 2017}




\section{International Journal of Science and Research (IJSR) \\ ISSN (Online): 2319-7064}

Index Copernicus Value (2016): 79.57 | Impact Factor (2015): 6.391

most researchers spend on it, so there are two main issues need to checked which are:

1) It is a state characterized by turbulent intellectual processes.

2) Such disturbed intellectual processes, or resulting in them, result in behavioral actions that affect the individual's compatibility with the environment in which he lives.

It is better to understand these two issues as character traits, since paranoia has been treated as a diagnostic category - a mental problem of whether or not the individual is suffering - and that a new conceptual alternative to paranoia should be presented as the result of a complex interaction of both structures and processes, and this seems to be possible in the eyes of a number of researchers if paranoia is seen as And that a new conceptual alternative to paranoia should be presented as the result of a complex interaction of both structures and processes, and this seems to be possible in the eyes of a number of researchers if paranoia is seen as a similar case to other personality Cases,In the sense that it can be described as a consistent and comprehensive pattern of thinking, feelings and explicit behavior, and that there is a fundamental element in this pattern, which can be determined across a wide range of individuals ranging from people with severe dysfunction to normal.

The results of the large number of research on paranoia and PPD come out with two main outcomes: agreement on a number of major symptoms, and a surprising lack of agreement on the components of PPD,, The Diagnostic System of the American Psychiatric Association (DSM) has conducted over the years, significant changes in the diagnostic standard of this disorder, and the debate remains about whether these were due to scientific reasons, or other factors (Turkat, et al., 1990, p. 312).

As documented in the above, and in further elaboration, the description of PPD is presented below. The last two images of the two most commonly used psychosomatic definitions, namely DSM-IV,And the International Classification of Diseases (ICD-10). The first classification (DSM -IV) is characterized by seven symptoms, if at least four are available, the patient is classified within this disorder, the symptoms are:

1) Doubts, without sufficient evidence, that others are exploiting or deceiving him.

2) Uncertainty about unjustified loyalty, loyalty, integrity or trust of friends, or those who are related to them.

3) Trust the others, because of unjustifiable fear, that the information will be used against him.

The World Health Organization (ICD-10) categorized the symptoms of PPD by seven, but only three were available in the individual to have the disorder, and the symptoms were

1) Excessive sensitivity to setbacks or obstacles, and rejection.

2) A tendency to carry a permanent grudge, and to refuse forgiveness for insults, injustice or contempt.

3) There is a general tendency to distort experience, including misunderstanding of neutral or friendly acts, and interpreting them as hostility or disdain.
4) Prepared to fight or resist, stubbornly insist on adhering to his personal rights, regardless of the practical situation.

5) Same formula in (7) above, from DSM-IV.

6) Excessive sense of self-importance, the self becomes the permanent reference direction.

7) Unjustifiable preoccupation with the interpretation of the events surrounding him or the world at his own capacity as an order against him (W.H.O. 1997, p.124).

If the expert emphasized the abnormal or abnormal perceptions, Bernstem et al.1993 stressed stress and the need for control. Zoroastrian thinking in its acute states sometimes expresses itself in situational or social situations like:Such as immigration, economic deprivation, imprisonment, compulsory military service and even having to leave the house. Although these conditions are multifaceted, they carry unequal or abnormal experiences, linked to severe social isolation, And unfamiliar with the appropriate rules of conduct, as well as the acute sense of exploitation, and the general loss of control over life.

A person who is falsely distributes blame from one's self to the other, in all the difficulties he faces, he believes that others are always responsible for his distaste and arrogance, and since this belief is not true in real terms, he aims to make reality a system and meaning in its own way, for example he does not believe that natural disasters or unintentional accidents occur indiscriminately. What happens, especially what is happening around it, is the result of an active act, and that this actor must be an enemy (the inventor) of this enemy, It holds him to blame for all that he has suffered and hurts him or the distress and impose, in this way (cognitive) form of the system and some sense of the reality in which he lives. Another similar explanation put by Swanson et al., 1970.they see that the reactions of people with falsehood, organized into a cognitive process that takes the form of a phantom system, are no different from the biased tendencies of a large number of individuals with strong belief systems, they see that the reactions of people with falsehood, organized into a cognitive process that takes the form of a phantom system, are no different from the biased tendencies of a large number of individuals with strong belief systems.

When paranords begin to complain that others are working against them, they take note of even the simple things and the light signals that go in the direction of their suspicions, and neglect all other evidence in the opposite direction. By relying on the frame of reference, Especially those with a high degree of competition, they find it easy to relax, to choose events that blend with their illusions, regardless of whether these events are innocent or free from bad faith. Swanson and his colleagues point out that, and they believe that this matter leads to mistrust and criticism of others, and others have to move away from them, and this makes the infected people in the friction continue with others, resulting in new events, they distort and amplify them. (Saleh, 2000 p. 131).

\section{Reasons for oppositional thinking}

The causes of atheistic thinking can be determined as follows: Personal factors and preparations prior to infection 


\section{International Journal of Science and Research (IJSR) \\ ISSN (Online): 2319-7064}

Index Copernicus Value (2016): 79.57 | Impact Factor (2015): 6.391

The individual may be characterized by personality traits and these characteristics develop according to individual growth. - Family environmental factors commonly associated with persecution in individualsand a sense of threat and insecurity and isolation, which helps to prepare individuals for the psychological preparation of the disease, if the other factors that lead to it. Psychological factorsSuch as psychological conflict, feelings of frustration or disappointment in the result of defeat or failure in competition or love, delayed marriage or spinsterhood, or as a result of sexual deprivation, including previous experiences (AlQureaiti, 1998, 385).

\section{Research procedures}

This chapter includes a description of the procedures carried out by the researcher, which is to determine the research community, describing the selection of a representative sample of him, and to clarify the adoption of an instrument for measuring the repression of emotional, and adopt another tool to measure thinking, and the achievement to be met by the scientific conditions to be available to them of sincerity, stability and discrimination to be valid for the achievement of research objectives as well as the statistical means used for data analysis and processing statistically.

\section{Research society}

The current research community is determined by the students of the University of Baghdad for the academic year 2017-2016 of (45281) students and distributed in (22) faculty, including scientific specialties, which has a total student (19891) students and humanities and the total number of students (25390) .

\section{Research sample}

The research sample consisted of (400) students (males and females) distributed in four faculties randomly selected from Baghdad University for the academic year (2016-2017), two in the scientific specialization and two in the human specialization.

The researcher chose to select the sample of his applied research on the random stratified method of equal distribution, and then the sections and rows were selected from each random college as well. The representation of the two sex variables was equal to 200 males and 200 females. (200) students of humanitarian competence, (200) students of scientific disciplines and the table shows that.

Table 1: Distribution of the sample of the research by specialization and gender

\begin{tabular}{|c|c|c|c|c|c|}
\hline \multirow{2}{*}{ Tota } & \multicolumn{2}{|c|}{ Gender } & \multirow[b]{2}{*}{ specilization } & \multirow{2}{*}{ faculty } & \multirow{2}{*}{ No. } \\
\hline & Female & Male & & & \\
\hline 100 & 50 & 50 & Human & ART & 1 \\
\hline 100 & 50 & 50 & Human & Education- Ibn rushd & 2 \\
\hline 100 & 50 & 50 & scientific & $\begin{array}{c}\text { Education- Ibn al } \\
\text { haitham }\end{array}$ & 3 \\
\hline 100 & 50 & 50 & scientific & $\begin{array}{c}\text { Economic and } \\
\text { management }\end{array}$ & 4 \\
\hline
\end{tabular}

\section{Research tools}

The measure of emotional repression The researcher adopted the measure of the emotional repression of the researcher Dr. Reem Khamis Mahdi 2013 The researcher has used the standards and knowledge of previous studies in the construction of the scale The scale contains seven alternatives (strongly agree, mostly agree,agree, Neutral, Disagree, Disagree Mostly, Disagree strongly (with weights $7,6,5,4,3,2,1)$.

\section{The validity of the paragraphs}

For the purpose of identifying the validity of the paragraphs (face validity) showed the paragraphs of the scale, the maximum (24) paragraph and alternatives to answer and demographic information required, a group of experts specializing in psychological measurement and educational science and psychological(10) experts and found that all paragraphs are valid.

\section{Sample of statistical analysis of the paragraphs}

Sample of statistical analysis of the paragraphs of the measure of the suppression of emotional discrimination Paragraphs after correcting the forms of the interviewer ranked the forms of the descending from the highest total to the lowest and then took the top $27 \%$ of the forms as having the highest degrees and called the highest group, it is total number is (108) form, and the lowest group with the lowest score and called the minimum group (108) form, and after having analyzed the paragraphs of this measure using the $\mathrm{T}$ test for two independent samples, and the value of the table $(1,96)$ at the level of semantics it is total number is $(108)$ form, and the lowest group with the lowest score and called the minimum group (108) form, and after having analyzed the paragraphs of this measure using the T-test for two independent samples, and the value of the table $(1,96)$ at the level of significant equal to (0.05) and freedom degree (214) and resulted that all paragraphs are distinguished when it compared with the tabular values.

Table 2: Parameters of discrimination of the measures of emotional repression

\begin{tabular}{|c|c|c|c|c|c|}
\hline \multirow[b]{2}{*}{$\begin{array}{c}\text { Calculated } \\
\text { T value }\end{array}$} & \multicolumn{2}{|c|}{ low group } & \multicolumn{2}{|c|}{ High group } & \multirow[b]{2}{*}{ No. } \\
\hline & $\begin{array}{l}\text { Standard } \\
\text { deviation }\end{array}$ & $\begin{array}{c}\text { Arithmetic } \\
\text { mean }\end{array}$ & $\begin{array}{l}\text { Standard } \\
\text { deviation }\end{array}$ & $\begin{array}{c}\text { Arithmetic } \\
\text { mean }\end{array}$ & \\
\hline 8.669 & 2.63 & 3.37 & \begin{tabular}{|l|}
1.37 \\
\end{tabular} & 2.18 & 1 \\
\hline 5.335 & 3.63 & 3.90 & 1.80 & 2.14 & 2 \\
\hline 8.392 & 2.11 & 3.30 & 2.30 & 3.29 & 3 \\
\hline 4.842 & 2.16 & 2.83 & 3.17 & 4.24 & 4 \\
\hline 6.566 & 2.39 & 3.08 & 3.38 & 4.59 & 5 \\
\hline 8.530 & 2.36 & 2.89 & 2.68 & 3.27 & 6 \\
\hline 5.281 & 2.18 & 3.82 & 2.76 & 4.83 & 7 \\
\hline 8.662 & 3.47 & 3.21 & 2.17 & 2.35 & 8 \\
\hline 4.716 & 4.12 & 2.82 & 2.59 & 3.49 & 9 \\
\hline 7,336 & 3.32 & 3.60 & 2.90 & 4.45 & 10 \\
\hline 7.711 & 3.66 & 3.88 & 1.55 & 4.45 & 11 \\
\hline 6.365 & 1.02 & 2.84 & 2.37 & 4.44 & 12 \\
\hline 4.564 & 2.08 & 3.64 & 2.36 & 4.03 & 13 \\
\hline 4.487 & 2.28 & 3.34 & 2.30 & 4.76 & 14 \\
\hline 4.612 & 3.01 & 3.21 & 2.44 & 3.37 & 15 \\
\hline 4.551 & 3.66 & 4.82 & 1.82 & 5.65 & 16 \\
\hline 4.521 & 2.73 & 3.24 & 1.14 & 4.59 & 17 \\
\hline 4.189 & 2.82 & 3.65 & 2.08 & 4.16 & 18 \\
\hline 4.912 & 3.81 & 3.68 & 1.29 & 3.00 & 19 \\
\hline 4.482 & 1.69 & 3.09 & 1.50 & 3.71 & 20 \\
\hline 4.661 & 2.21 & 3.23 & 1.10 & 3.53 & 21 \\
\hline 8.691 & 2.24 & 3.49 & 1.65 & 3.53 & 22 \\
\hline 4.201 & 1.48 & 1.81 & 1.65 & 2.38 & 23 \\
\hline 5.519 & 3.21 & 3.75 & 1.89 & 4.30 & 24 \\
\hline
\end{tabular}

\section{Volume 6 Issue 12, December 2017}




\section{International Journal of Science and Research (IJSR) \\ ISSN (Online): 2319-7064}

Index Copernicus Value (2016): 79.57 | Impact Factor (2015): 6.391

Table 3: Interaction coefficients of the measure of emotional suppression with the total degree of the scale

\begin{tabular}{|c|c|c|c|}
\hline Coefficient value & No. & Coefficient value & No. \\
\hline 0.312 & 13 & 0.542 & 1 \\
\hline 0.306 & 14 & 0.493 & 2 \\
\hline 0.458 & 15 & 0.485 & 3 \\
\hline 0.336 & 16 & 0.482 & 4 \\
\hline 0.322 & 17 & 0.331 & 5 \\
\hline 0.290 & 18 & 0.437 & 6 \\
\hline 0.327 & 19 & 0.353 & 7 \\
\hline 0.374 & 20 & 0.446 & 8 \\
\hline 0.223 & 21 & 0.363 & 9 \\
\hline 0.0417 & 22 & 0.412 & 10 \\
\hline 0.342 & 23 & 0.524 & 11 \\
\hline 0.366 & 24 & 0.318 & 12 \\
\hline
\end{tabular}

\section{Reliability}

Test - Retest Method The emotional suppression scale was applied to a sample of 30 students from the Faculty of Education Ibn Al - Haytham. It was re - applied to the same sample after a period of 14 days and after using the person coefficient factor,It was found that the correlation coefficient was (0.862) and this value is acceptable in correlation coefficients. - The Alfa cronbach method after applying the
Alfa cronbach equation showed that the correlation coefficient of the emotional suppression measure (0.89).

\section{Validity of Scale}

\section{Face Validity}

Achieve this kind of honesty by presenting the paragraphs of the scale and its alternatives and instructions to a group of experts and specialists in psychology as mentioned earlier.

\section{The dimension of oppressive thinking}

After studying the literature and previous studies related to the subject of atheistic thinking, the 'Perspective Thinking' scale prepared by Saeed was adopted and adopted in building the scale on the views of psychiatrists and psychologists as well as (DSMIV), which consists of (56) paragraphs, although the alternatives to response to the scale are (always, often, rarely, not applicable) in weights $(5,4,3$, $2,1)$, respectively. Validity of paragraphs to check the validity of paragraphs to verify the validity of the paragraphs of the scale of thinking atheist The paragraphs of the scale was presented in its initial form to a group of experts in education and psychology number (10) experts and found that all paragraphs valid

Table 4: of expert opinions of the scale of oppressive thinking

\begin{tabular}{|c|c|c|c|c|}
\hline percentage & $\begin{array}{c}\text { Non } \\
\text { accepted } \\
\text { persons }\end{array}$ & $\begin{array}{c}\text { accepted } \\
\text { persons }\end{array}$ & paragraphs & $\begin{array}{c}\text { No. of } \\
\text { paragraphs }\end{array}$ \\
\hline $100 \%$ & - & 10 & 1 & 42 \\
& & & $22,23,26,27,30,33,34,35,36,37,39,40,41,43,44,45,46,47,48,49,50,51,53,54,55,56$ & \\
\hline $90 \%$ & & 9 & $2,7,10,13,14,24,25,28,29,31,32,38,42,52$ & 14 \\
\hline
\end{tabular}

In order to determine the clarity of the instructions of the scale and its terms in terms of formulation and meaning, the scale of thinking was applied to 25 students from the Faculty of Education Ibn al-Haytham, asking them to read the instructions and paragraphs and answer them and to inquire about any ambiguity facing them.It was found that the scales and instructions were clear to the respondents, and that the average time taken to respond to the scales was 18 minutes.

\section{Sample of Statistical Analysis of the Paragraphs of the Disciplinary Thinking}

Scale 1. Marking the Paragraphs After correcting the forms of the examinees, the researcher arranged the forms down from the highest to the lowest grade. The top (27\%) of the forms were taken as highest scores, where the number of scale is (108), and in the lower group with the lowest score, called the minimum group and the number of (108) form, and after the paragraphs of this measure were analyzed using the test of two independent samples, and the value of the table $(1,96)$ at significant level of $(0,05)$ and degree of freedom (214). It was found that all the paragraphs are distinct when compared to the table value. Table (5) shows that:
Table 5: The coefficients of the distinction between the dimensions of the ideology of the radical groups

\begin{tabular}{|c|c|c|c|c|c|}
\hline \multirow[b]{2}{*}{$\begin{array}{c}\text { Calculated } \\
\mathrm{T} \text { value }\end{array}$} & \multicolumn{2}{|c|}{ low group } & \multicolumn{2}{|c|}{ High group } & \multirow[b]{2}{*}{$\begin{array}{c}\text { Paragraph } \\
\text { no. }\end{array}$} \\
\hline & $\begin{array}{l}\text { Standard } \\
\text { deviation }\end{array}$ & mean & $\begin{array}{c}\text { Standard } \\
\text { Deviation }\end{array}$ & mean & \\
\hline 9,148 & 1,231 & 1,283 & 1,355 & 2,525 & 1 \\
\hline 8,714 & 1,227 & 1,318 & 1,306 & 2,705 & 2 \\
\hline 8,607 & 1,311 & 2,193 & 1,118 & 3,689 & 3 \\
\hline 8,255 & 1,115 & 1,239 & 1,816 & 2,265 & 4 \\
\hline 1,079 & 1,312 & 2,230 & 1,323 & 2,601 & 5 \\
\hline 6,555 & 1,201 & 2,160 & 1,302 & 2,193 & 6 \\
\hline 9,966 & 1,615 & 2,211 & 1,242 & 1,535 & 7 \\
\hline 6,623 & 1,280 & 2,222 & 1,283 & 2,233 & 8 \\
\hline 10,414 & 0,951 & 1,535 & 1,401 & 2,635 & 9 \\
\hline 9,252 & 0,911 & 1,726 & 1,306 & 1,265 & 10 \\
\hline 10,695 & 1,108 & 2,834 & 1,224 & 1,200 & 11 \\
\hline 8,192 & 1,282 & 1,643 & 1,215 & 2,099 & 12 \\
\hline 7,671 & 1,216 & 1,326 & 1,151 & 2,233 & 13 \\
\hline 9,333 & 0,211 & 2,554 & 1,720 & 2,134 & 14 \\
\hline 8,362 & 0,149 & 1,810 & 1,341 & 2,108 & 15 \\
\hline 11,242 & 0,713 & 1,560 & 1,381 & 2,962 & 16 \\
\hline 10,310 & 0,813 & 2,179 & 1,178 & 2,338 & 17 \\
\hline 13,613 & 0,921 & 1,196 & 1,382 & 2,323 & 18 \\
\hline 12,311 & 1,706 & 1,124 & 1,222 & 2,517 & 19 \\
\hline 8,516 & 1,213 & 1,315 & 1,468 & 2,219 & 20 \\
\hline 6,219 & 1,455 & 2,251 & 1,212 & 2,288 & 21 \\
\hline 7,333 & 0,661 & 1,291 & 1,521 & 1,266 & 22 \\
\hline 9,691 & 1,228 & 2,612 & 1,212 & 2,356 & 23 \\
\hline 7,822 & 0,782 & 0,311 & 1,252 & 1,150 & 24 \\
\hline 12,782 & 0,629 & 0,426 & 1,610 & 2,353 & 25 \\
\hline 12,232 & 1,136 & 0,835 & 1,432 & 2,381 & 26 \\
\hline
\end{tabular}

Volume 6 Issue 12, December 2017 


\section{International Journal of Science and Research (IJSR) \\ ISSN (Online): 2319-7064}

Index Copernicus Value (2016): 79.57 | Impact Factor (2015): 6.391

\begin{tabular}{|c|c|c|c|c|c|}
\hline 8,553 & 1,342 & 1,712 & 1,222 & 2,583 & 27 \\
\hline 8,233 & 1,331 & 1,428 & 1,621 & 2,312 & 28 \\
\hline 8,816 & 0,961 & 0,793 & 1,555 & 2,018 & 29 \\
\hline 14,163 & 0,999 & 0,752 & 1,317 & 2,881 & 30 \\
\hline 12,617 & 0,891 & 0,563 & 1,416 & 2,562 & 31 \\
\hline 12,114 & 0,982 & 0,989 & 1,283 & 2,867 & 32 \\
\hline 10,485 & 0,622 & 0,258 & 1,518 & 1,826 & 33 \\
\hline 10,584 & 1,223 & 1,083 & 1,235 & 2,671 & 34 \\
\hline 10,335 & 0,926 & 1,265 & 1,281 & 2,831 & 35 \\
\hline 13,171 & 0,956 & 0,787 & 1,398 & 2,612 & 36 \\
\hline 11,323 & 0,956 & 0,684 & 1,521 & 2,222 & 37 \\
\hline 11,663 & 0,771 & 0,470 & 1,462 & 2,115 & 38 \\
\hline 13,681 & 0,878 & 0,688 & 1,373 & 2,521 & 39 \\
\hline 14,412 & 0,991 & 0,881 & 1,433 & 2,661 & 40 \\
\hline 13,339 & 0,916 & 0,496 & 1,415 & 2,218 & 41 \\
\hline 14,718 & 1,153 & 0,977 & 1,282 & 2,201 & 42 \\
\hline 12,776 & 0,899 & 0,857 & 1,285 & 2,482 & 43 \\
\hline 12,151 & 0,923 & 0,911 & 1,353 & 2,821 & 44 \\
\hline 8,317 & 1,225 & 1,762 & 1,223 & 2,292 & 45 \\
\hline 6,818 & 1,254 & 1,298 & 1,488 & 2,313 & 46 \\
\hline 9,422 & 1,315 & 1,296 & 1,410 & 2,676 & 47 \\
\hline 12,477 & 0,966 & 1,548 & 1,256 & 2,718 & 48 \\
\hline 10,256 & 1,161 & 1,434 & 1,386 & 2,261 & 49 \\
\hline 7,675 & 1,021 & 0,794 & 1,461 & 2,126 & 50 \\
\hline 13,217 & 0,912 & 0,752 & 1,313 & 2,322 & 51 \\
\hline & & & & \\
\end{tabular}

\begin{tabular}{|l|l|l|l|}
\hline 0,356 & 50 & 0,382 & 22 \\
\hline 0,431 & 51 & 0,436 & 23 \\
\hline 0,428 & 52 & 0,432 & 24 \\
\hline 0,349 & 53 & 0,438 & 25 \\
\hline 0,425 & 54 & 0,470 & 26 \\
\hline 0,426 & 55 & 0,462 & 27 \\
\hline 0,433 & 56 & 0,361 & 28 \\
\hline
\end{tabular}

)0.098 (at a significance level $(0,05)$ and a degree of freedom (398). When using this method, the researcher used the same data by finding the relationship between the scores of the individuals on each paragraph and their total scores on the scores of all the paragraphs of the scale. All the paragraphs of this scale were found to be distinct. Reliability and Stability Indicators Reliability - Test - Retest Method The measure of stress was applied to a sample of 30 students from the Faculty of Education Ibn Al - Haitham.It was reapplied to the same sample after 14 days and after using the Pearson correlation coefficient, it was found that the correlation coefficient was 0.83 and this value is acceptable in the correlation coefficients.- The alfa cronbach method after the application of the alfa cronbach equation that the coefficient of correlation of the scale of oppressive thinking (0.87).

Table 6: Pearson correlation coefficients to the degree of the paragraph in the overall degree of the measurement of atherosclerosis

\begin{tabular}{|c|c|c|c|}
\hline معامل ارتباط (*) & رقم الفقرة & معامل الارتباط(") & رقم الفقرة \\
\hline 0,385 & 29 & 0,432 & 1 \\
\hline 0,471 & 30 & 0,462 & 2 \\
\hline 0,468 & 31 & 0,391 & 3 \\
\hline 0,566 & 32 & 0,461 & 4 \\
\hline 0,481 & 33 & 0,462 & 5 \\
\hline 0,363 & 34 & 0,338 & 6 \\
\hline 0,481 & 35 & 0,431 & 7 \\
\hline 0,428 & 36 & 0,362 & 8 \\
\hline 0,464 & 37 & 0,497 & 9 \\
\hline 0,436 & 38 & 0,385 & 10 \\
\hline 0,423 & 39 & 0,446 & 11 \\
\hline 0,392 & 40 & 0,371 & 12 \\
\hline 0,462 & 41 & 0,363 & 13 \\
\hline 0,555 & 42 & 0,431 & 14 \\
\hline 0,486 & 43 & 0,383 & 15 \\
\hline 0,497 & 44 & 0,461 & 16 \\
\hline 0,391 & 45 & 0,433 & 17 \\
\hline 0,373 & 46 & 0,492 & 18 \\
\hline 0,423 & 47 & 0,422 & 19 \\
\hline 0,456 & 48 & 0,377 & 20 \\
\hline 0,470 & 49 & 0,395 & 21 \\
\hline
\end{tabular}

\section{Validity of Scale}

Validation of this type of honesty is achieved by presenting the scale paragraphs on a group of experts and specialists in psychology as mentioned previously. substitutions and instructions on the total

\section{Results}

This paragraph includes a presentation of the researcher's findings and their interpretation in the light of the theoretical framework and the recommendations and suggestions based on them.

1. Measuring the emotional repression of university students The first objective in this research is to measure the emotional repression of university students. The results of the study show that the mathematical mean of the scores of the sample of 400 students reached (102.52) and a standard deviation of (12.19) and a presumed mean (96) And for the purpose of comparing the arithmetic mean For the sample samples in the mean of the scale, the T-test was used for one sample. Table (7) shows the results of this test.

Table 7: Arithmetic mean, standard deviation and $\mathrm{T}$ value of the sample of the research sample of the emotional suppression scale

\begin{tabular}{|c|c|c|c|c|c|c|c|c|}
\hline results & $\begin{array}{c}\text { Significant } \\
\text { level }\end{array}$ & $\begin{array}{c}\text { tabular } \\
\text { t value }\end{array}$ & $\begin{array}{c}\text { Calculated } \\
\text { t value }\end{array}$ & $\begin{array}{c}\text { Freedom } \\
\text { degree }\end{array}$ & $\begin{array}{c}\text { Supposed } \\
\text { mean }\end{array}$ & $\begin{array}{c}\text { Standard } \\
\text { deviation }\end{array}$ & $\begin{array}{c}\text { Arithmetic } \\
\text { mean }\end{array}$ & $\begin{array}{c}\text { No. of } \\
\text { sample }\end{array}$ \\
\hline significant & 0.01 & 2.576 & 10.69 & 399 & 96 & 12.19 & 102.52 & 400 \\
\hline
\end{tabular}

Table (7) shows that the computational mean of the current research sample exceeds the mean mean of the scale with statistical significance at the level of significance (0.01) and that the calculated $\mathrm{T}$ value is greater than the tabular value. This means that members of the current research sample have an emotional suppressive and can explain The interpretation of this result in the light of the suffering suffered by the Iraqi society for more than a decade and the associated security, political and social crises and the nature of cultural structures and some methods of social and family upbringing erroneous, and shocking events experienced by the Iraqi individualhas formed a pattern of emotional repression as a strategy to avoid traumatic experiences and suppress the resulting emotions, and generated lifestyles that are characterized by continuous suppression of their emotions and curbing the freedom of emotional expression

\section{Volume 6 Issue 12, December 2017}

\section{www.ijsr.net}

Licensed Under Creative Commons Attribution CC BY 


\section{International Journal of Science and Research (IJSR) \\ ISSN (Online): 2319-7064}

Index Copernicus Value (2016): 79.57 | Impact Factor (2015): 6.391

and openness to others. This indicates that the methods of social and family upbringing have failed in how to deal with their children in managing their emotions. The 1996 Fox study confirmed that the period between early childhood and adolescence is important and its role in directing individuals to positive and successful organizational styles of their emotions, or they may fail according to the pattern of upbringing and the family surrounding them.

The study emphasizes the amount of damage caused by restraining the individual for their feelings because they form the foundation stone in the way he thinks in the situations he is going through.According to the researcher, community members did not receive sufficient support from the social support given to them. As a result of some social criteria and some methods of family upbringing, they did not have the opportunity to learn to express their emotions (fears, concerns, feelings, disorders).

This is reflected in the suppression of their emotions for fear of the social and family consequences of their emotional expressions in a situation, and this generates a long series of negative psychological effects and as members of Iraqi society have an emotional repression as indicated by the results, there are negative indicatorsresults from it, Gross pointed out that emotional suppression (Emotional Suppression).'Individuals are forced to act cautiously with their emotions, leading them to a growing sense of tension, social falsity and a negative feeling towards themselves, leading them to experience of negative influence and subsequent depressive symptoms.' Crosse also stressed that emotional repression reducesthe attribute of the diastolic in the members to appear over time the manifestations of social shame, and that the attribute of shame, prompting individuals to suppress the same repressive method for fear of the emergence of inappropriate signals from others towards them (John and Gross, 2004, pp. 1321-1322).

2.The results showed that the arithmetic mean of the emotional suppression of the male sample was $(84,90)$ and the standard deviation $(10,74)$, while the arithmetic mean of the emotional suppression of the female sample was $(88,70)$ ) And a standard deviation of (110.30)Using the T-test for two independent samples, the extracted $\mathrm{T}$ value was (11.5) and the table value $(2,576)$ was shown to be a function at the mean level (0.01), indicating a statistically significant difference for the benefit of the female.

Table 8: Measuring the differences in emotional repression according to gender variable (male / female)

\begin{tabular}{|c|c|c|c|c|c|c|c|}
\hline $\begin{array}{c}\text { Significant } \\
\text { level }\end{array}$ & $\begin{array}{c}\text { tabular t } \\
\text { value }\end{array}$ & $\begin{array}{c}\text { Calculated t } \\
\text { value }\end{array}$ & $\begin{array}{c}\text { Freedom } \\
\text { degree }\end{array}$ & $\begin{array}{c}\text { Supposed } \\
\text { mean }\end{array}$ & $\begin{array}{c}\text { Standard } \\
\text { deviation }\end{array}$ & $\begin{array}{c}\text { Arithmetic } \\
\text { mean }\end{array}$ & $\begin{array}{c}\text { No. of } \\
\text { sample }\end{array}$ \\
\hline significant & 0.01 & 398 & 2.576 & 11.5 & 10.74 & 84.90 & male \\
\cline { 6 - 9 } & & & & & & &
\end{tabular}

This result can be attributed to the fact that qualitative differences between males and females indicate that females receive a different kind of emotional formation compared to males. Although the sample has an emotional suppression of both sexes, females have higher emotional suppression than males in the study sample. This is due to the nature of the culture and family upbringing from which the individual descends. The influence of males and females depends on the nature of the intellectual structure of the society and its view of individual freedom both inside and outside the family.

3. Reem, in her study focus on emotional repression in 2013 , points out that parenting styles are a major reason behind individuals' attempts to suppress or conceal the truth of their feelings. The approach is based on rigor, cruelty, neglect, disregard for their feelings or thinking, And ignore the views expressed or underestimated contribute to the marginalization of the construction of his personality, and loss of confidence itself over time, which takes the appearance of exaggerated in the integration with others without drawing limits to his personality and psychological field or vice versa, namely, taking a negative attitude and inability to expressing his opinion and fear of the responsibility resulting from it and it is all in the amount of freedom of expression granted since childhood.

4. The results showed that the mean of the scores of the individuals of the research sample for the scale of thinking was $(175,12)$ and the standard deviation of $(15.73)$ and the mean mean of (168). For the purpose of comparing the mathematical mean of the sample of the research with the supposed mean of the sample of research. Where the T-test was used for one sample. The mean was superior to the mean of the scale. It was statistically significant at the level of significance $(0.01)$ and the calculated $\mathrm{T}$ value was greater than the tabular value.

Table 9: The arithmetic mean, the standard deviation, and the calculated $\mathrm{T}$ value of the sample members of the research sample for the measurement of oppressive thinking

\begin{tabular}{|c|c|c|c|c|c|c|c|c|}
\hline Result & $\begin{array}{c}\text { Significant } \\
\text { level }\end{array}$ & $\begin{array}{c}\text { tabular } \\
\text { t value }\end{array}$ & $\begin{array}{c}\text { Calculated } \\
\text { t value }\end{array}$ & $\begin{array}{c}\text { Freedom } \\
\text { degree }\end{array}$ & $\begin{array}{c}\text { Supposed } \\
\text { mean }\end{array}$ & $\begin{array}{c}\text { Standard } \\
\text { deviation }\end{array}$ & $\begin{array}{c}\text { Arithmetic } \\
\text { mean }\end{array}$ & $\begin{array}{c}\text { No. of } \\
\text { sample }\end{array}$ \\
\hline significant & 0.01 & 2.576 & 9.05 & 399 & 168 & 15.73 & 175.12 & 400 \\
\hline
\end{tabular}

The results indicate that the level of oppressive thinking among the university students is greater than the accepted mean. This means that the respondents have oppressive thinking. This result can be explained by the fact that the pressures, crises and traumatic events that have been exposed to the Iraqi society for more than a decade of wars and security and political crises that generated negative effects on the individual, the family and society, produced tendencies of atheistic thinking (fear and suspicion of others' intentions, non-adaptive feelings, irrational beliefs, erroneous assumptions of events and attitudes, And the tendency to interpret the actions and intentions of others as a 


\section{International Journal of Science and Research (IJSR) \\ ISSN (Online): 2319-7064}

Index Copernicus Value (2016): 79.57 | Impact Factor (2015): 6.391

threat and intentional and humiliating, and this result is consistent with the results of several studies reported that many of the characteristics of atheistic thinking exist in ordinary people in the community who are exposed to similar crises as a study (Thomposon and Turkat)( Fenigstein and vanable, 1990).
The results showed that the mean of the male sample was (86.39) and the standard deviation was $(11,27)$ while the mathematical mean of the female sample was (86.14) and by standard deviation Capacity $(11,21)$ and using the $t$ test for two independent samples, the extracted $\mathrm{T}$ value was $(0.745)$ compared to the table value (1.96), which is insignificant at $(0.05)$ indicating that there are no differences in oppressive thinking between males and females.

Table 9: Measurement of differences in the thinking of the oppressive according to gender variable (male and female)

\begin{tabular}{|c|c|c|c|c|c|c|c|c|}
\hline result & $\begin{array}{c}\text { Significant } \\
\text { level }\end{array}$ & $\begin{array}{c}\text { tabular } \\
\mathrm{t} \text { value }\end{array}$ & $\begin{array}{c}\text { Calculated } \\
\mathrm{t} \text { value }\end{array}$ & $\begin{array}{c}\text { Freedom } \\
\text { degree }\end{array}$ & $\begin{array}{c}\text { Supposed } \\
\text { mean }\end{array}$ & $\begin{array}{c}\text { Standard } \\
\text { deviation }\end{array}$ & $\begin{array}{c}\text { Arithmetic } \\
\text { mean }\end{array}$ & $\begin{array}{c}\text { No. of } \\
\text { sample }\end{array}$ \\
\hline $\begin{array}{c}\text { Not } \\
\text { significant }\end{array}$ & 0.05 & 398 & 1.96 & 0.745 & 11.27 & 86.39 & 200 & male \\
\cline { 5 - 10 } & & & & & & & &
\end{tabular}

This result can be attributed to the fact that the pressures, crises and traumatic events that have been exposed to the Iraqi society and the security and political crises that have afflicted the individual, family and society have had the same effect and suffering for both genders.

The extent of male negative effects of circumstances and crises of fear, non-adaptive feelings, irrational beliefs, erroneous assumptions about events and attitudes, and a tendency to interpret the actions and intentions of others as threatening, intentional and humiliating are the same as the negative effects Which also affected females as a result of similar circumstances, attitudes and events.
To measure the correlation between emotional repression and oppressive thinking in order to identify the relationship between emotional repression and oppressive thinking among university students. The researcher applied Pearson correlation coefficient between the two variables. The coefficient of correlation (0.73)the test was used to calculate the significance of this correlation. The t-test was calculated using the calculated $\mathrm{T}$ value balance of (22.52) in the table value of $(2,576)$ at the level of significance $(0.01)$ and the degree of freedom (398) was found to have a high level of morale. It is clear that there is a positive correlation between emotional repression and oppressive thinking.

Table 10: Measuring the correlation between emotional repression and oppressive thinking

\begin{tabular}{|c|c|c|c|c|c|c|}
\hline $\begin{array}{c}\text { tabular t } \\
\text { value }\end{array}$ & $\begin{array}{c}\text { Calculated } \mathrm{t} \\
\text { value }\end{array}$ & $\begin{array}{c}\text { Freedom } \\
\text { degree }\end{array}$ & $\begin{array}{c}\text { Supposed } \\
\text { mean }\end{array}$ & $\begin{array}{c}\text { Standard } \\
\text { deviation }\end{array}$ & $\begin{array}{c}\text { Arithmetic } \\
\text { mean }\end{array}$ & $\begin{array}{c}\text { No. of } \\
\text { sample }\end{array}$ \\
\hline significant & 0.01 & 398 & 0.73 & 2.576 & 22.52 & 400 \\
\hline
\end{tabular}

This indicates that individuals who have an emotional suppression contribute to the rise of oppressive thinking and vice versa, where the theories suggest that the link between thinking and emotion as a part of the expression and mutual influence shows how much emotional affect on thinking, any disturbance of thinking is accompanied by a disturbance of emotion and vice versa, and the emotional tendency toward a position is closely linked to thinking. This indicates that individuals who have an oppressive thought.

Oppressive feelings of suspicion and suspicion of the intentions of others, non-adaptive feelings, irrational beliefs, assumptions and misinterpretations of events and attitudes, and a tendency to interpret the actions and intentions of others as threatening, intentional and humiliating tend to suppress and hide their feelings because of The emotional intensity associated with the situation, as well as avoid negative social responses towards them, and are inclined to hide their suffering from difficult situations as a result of their sense of oppressive thinking.

\section{Recommendations}

In the light of the findings of the current research, the researcher recommends the following:

1) Work on the establishment of future studies and research to identify students suffering from emotional repression and oppressive thinking to take the necessary measures to enable the student to make it more effective when facing life problems.

2) 2.Establish therapeutic and guidance programs and prepare cadres specialized in cognitive behavioral therapy and EMDR treatment for those suffering from emotional repression, oppression and finding appropriate solutions.

\section{Proposals}

To supplement the requirements of this research, the researcher proposed a number of scientific studies and researches.

1) Conducting other studies dealing with the relationship of emotional repression with A.Stress management strategies. B. Depression.

2) Conduct studies dealing with the relationship of atheistic thinking A. Parental treatment methods. B. Social support.

\section{References}

[1] Al-Issawi, Mohamed Abdel Rahman, (2008) Prevention and treatment of mental disorders, Hala Publishing and Distribution House, Al-Hayza, Egypt.

[2] Al-Kriti, Abdul Muttalib Amin, (1998) in Mental Health, Cairo, Dar Al-Fikr Al-Arabi.

[3] Saleh, Qassem Hussein, (2000) Thinking of the situation and its relation to the dimensions of personal, 


\section{International Journal of Science and Research (IJSR) \\ ISSN (Online): 2319-7064}

Index Copernicus Value (2016): 79.57 | Impact Factor (2015): 6.391

unpublished doctoral thesis, Faculty of Arts, University of Baghdad, Baghdad, Iraq.

[4] Kamal, Ali, (1987) schizophrenia schizophrenia, Baghdad, Dar Wasit for studies and publication.

[5] Bernstein , D.P; Useds , D \& Siever, L.J.(1993) : Paranoid Personality disorder : Review of the literature and recommendations for DSM - IV , Journal of personality Disorders , 7, 53- 62.

[6] Bonanno George A.el.al.(2003) : the Importance of Being Flexible : the Ability to both Enhance and suppress emotional expression predicts long - term Adjustment clinical psychology program, Teachers college , Columbia university , U.S.A.

[7] Butler, Emily A. et.al (2007) : Emotion Regulation and Culture : Are the Social Consequences of Emotion suppression Culture - specific ? : Emotion journal the American psychological Association, Inc. U.S.A., VoI . 7. N1.

[8] Costello, C.G.(1996) , Personality characteristics of the Personality Disorders . Disorders , New York: John Wiley \& Sons, Inc.

[9] Degirolamo,G.and Rrich,J.H.(1993).personality disorders geneva:World Health Organization.

[10]Fenigsten, A.(1995) , Paranoia and self- focused attention, Kluwer Acadimic publishers.

[11]Fucito , Lisa M .et .al.(2010): Cognitive Reappraisal and Expressive Suppression Emotion Regulation strategies in cigarette Smokers, Nicotine \& Tobacco Research , oxford university press , UK, Vol.12, No.11.

[12] Gross ， James (2007): Handbook of Emotion Regulation Guilford press, Ny, U.S.A.

[13] Gross, James and John , Oliver , P.(2003): Individual Differences in two Emotion Regulation Processes : Implications for Affect Relationships, and well - Being , Journal of Personality and Social Psychology, American Psychological Association, U.S.A, Vol, 85. Noz.

[14] John , Oliver P.and Gross , Jowes J. (2004) : Health and Unhealthy Emotion Regulation :Personality Processes, Individual Differences, and Life Span Development, Journal of Personality , Blackwell Publishing , U.S.A., Vol. 72, No.6.

[15] Mayer , E.R.(1977) . Thinking and problem- solving ( $2^{\text {nd }}$ eds), New Jersey : scott company.

[16] Mcleren , Karla(2010): The Language of Emotions , Sounds True, Inc., Toronto, Canada.

[17] Nezlek, John B.and Kuppens , Peter (2008) : Regulating Positive and Negative Emotions in Daily Life, Journal of Personality, Blackwell Publishing, Inc , U.S.A , Vol. 76, No.3.

[18] Pedneault , Kristalyn salters et.a;.(2010): suppression , from book of Emotion Regulation and Psychopathology, The Guilford press, Ny, U.S.A.

[19]Richards , Jane m. And Gross, Jawes (2005): Personality and Emotional Memory : How regulating emotion impairs memory for emotional events , Journal of Research in Personality , the Elsevier, Inc., U.S.A.

[20] Schneider , Kristin Grace (2008) : Expressive Control and Emotion perception : the Impact of Expressive Suppression and Mimicry on sensitivity to Facial Expressions of Emotion, A Dissertation of a Doctor
Degree in philosophy Department psychology and Neuroscience in the Gradual school, Duke university, U.S.A.

[21]Spokas , Megan et.al .2009) : Social Anxiety and Emotional suppression : the mediating Role of Beliefs , Journal of Behavior therapy and Experimental psychiatry, The Elsevier Ltd., U.S.A. Vol.40.

[22] Swanson, D.W; bohnert, p.J. \& Smith , J.A.(1970). The personality . Boston : Little, Brown.

[23] Turkat, I. D; Keane, S.P \& Thompson - pope, S.K.(1990).Social processing errors among paranoid personality. Journal of Psychopathology and Behavioral Assessment, 12, 263- 269.

[24] World Health Organization , (1992):International Statistical classification of diseases and related health problems, $\left(10^{\text {th }}\right.$. ed $)$, New York. 